RO BERTO HELO AN I

\title{
Vivendo no
}

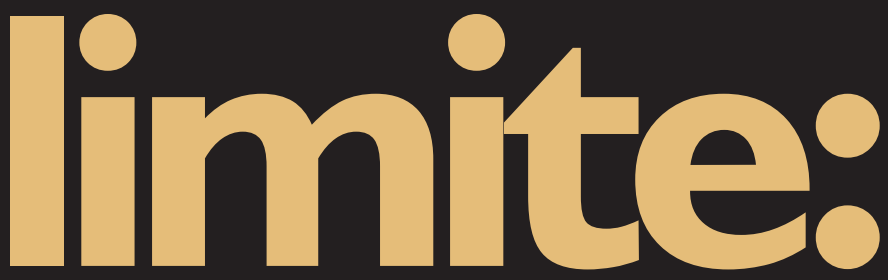

quem são

nossos

formadores de

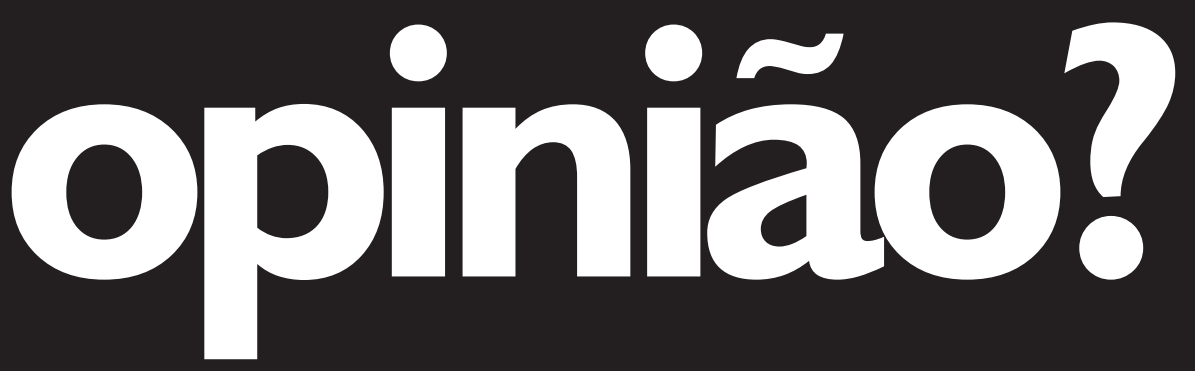




\section{“O preço queoshomenspagam pelo aumento deseu poder éaalienação daquilo sobreo queexercem o poder" (A dorno\& H orkheimer, 1986).}

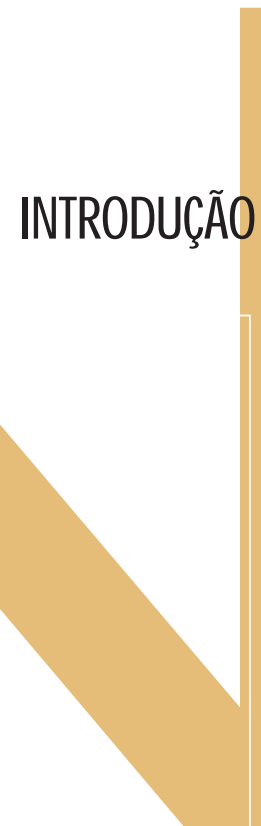

Este trabalho foi aprovado e financiado pelo Núcleo de Pesquisas e Publicações (N PP) da FG V-SP.

ROBERIOHBOAN

é professor da Faculdade de Educação da Unicamp, da FGV e da Unimarco. mentadas nas empresas, obrigando o trabalhador a adaptar-se rapidamente a elas e impondo-lhe um novo perfil profissional.

Neste novo contexto econômico em que os salários sofrem cada vez mais reduções e a educação emerge como a principal ferramenta de atualização, o trabalho torna-se cada vez mais precário e seletivo. O Estado vem, por meio de uma ideologia neoliberal, retirar e diminuir benefícios e direitos do trabalhador, alterando a relação capital-trabalho; surgem, então, novas relações, como o contrato de trabalho por tempo determinado, que geram, desse modo, o subem- 
prego e o trabalho informal, outra ameaça ao trabalhador, que antes tinha resguardados alguns direitos historicamente conquistados.

Outrossim, “gurus” e consultores organizacionais tentam conciliar e harmonizar, com discursos de cooperação e de trabalho em equipe, dois sujeitos historicamente desiguais - capital e trabalho - , perpetuando o paradoxo da necessidade de cooperação em equipe e a competição pela aquisição e manutenção de um posto de trabalho (Heloani, 2000, pp. 17-8; 2003, pp. 30-1).

David Harvey indica que mudanças abissais vêm ocorrendo nas práticas político-econômicas e culturais. Ao explicitálas, considera que, "quando confrontadas com as regras básicas de acumulação capitalista, mostram-se mais como transformações de aparência superficial, do que como sinais do surgimento de alguma sociedade pós-capitalista ou mesmo pós-industrial inteiramente nova" (Harvey, 1992, p. 7).

Desse modo, ainda que fazendo usos reiterados do termo novo-tal como: "novo ciclo de compressão do tempo-espaço na organização do capitalismo”, "novas condições do mercado de trabalho", "formas industriais totalmente novas", "uso de novas tecnologias produtivas e de novas formas organizacionais"; "nova aristocracia do trabalho" e "explosão de novos instrumentos e mercados financeiros" -, o autor considera a relatividade da alusão ao termo novo frente às invariâncias dos processos capitalistas (Harvey, 1992, p. 7).

De fato, uma das questões mais enfatizadas na era da globalização e do regime de acumulação flexível vai de encontro a um elemento invariante da lógica capitalista: o papel crucial da inovação organizacional e tecnológica. Ao lado desse elemento invariante, Harvey (1992, p. 166) considera outros dois: o capitalismo orientado para o crescimento e a exploração do trabalho vivo.

Ao abordar a questão da flexibilidade e da transição do período de acumulação rígida do fordismo-keynesiano para o período da acumulação flexível, conclui que as referidas modificações radicais convivem com "forças plasmadoras invariantes", afirmando que "não há nada essencialmente novo no impulso para a flexibilidade" (Harvey, 1992, pp. 15 e 178).

Harvey (1992, pp. 145-50) salienta que o surgimento das novas tecnologias se dá em processos produtivos que incluem o retorno às estratégias de extração de mais-valia absoluta por intermédio da retomada de sistemas de trabalho doméstico, familiar e paternalista. Ressalta que, sob a dependência de tais sistemas, colateralmente engendrados, instituições poderosas se fortalecem. Desse modo, a oposição entre a versão retumbante da velha história do capitalismo versus a nova configuração histórica merece ser visualizada não exatamente como uma dicotomia, mas como uma dialética de uma estrutura econômica e social marcada por antagonismos e contradições.

Assim, o que esse autor argumenta é que na transição por ele analisada se estabelece um novo bastante relativo, uma vez que este se coaduna com o ressurgimento da dominação paternalista e de "formas antigas de processo de trabalho e de produção pequeno-capitalista" (Harvey, 1992, pp. 145-50). Assim sendo, o novo não é exatamente novo, mas uma espécie de nova edição, que reedita elementos antigos travestidos em novas linguagens, tanto econômicas quanto produtivas e estéticas.

\section{UMA BREVE HISTÓRIA DA EXPRESSÃO "QUALIDADE DE VIDA"}

Contrariamente ao que foi preconizado no início dos anos de 1950-60 - de que a busca por qualidade de vida no trabalho (QVT) levaria a maior produtividade -, o movimento de QVT e a lógica da produtividade foram, paulatinamente, se dicotomizando em vetores díspares: enquanto o termo QVT aponta para a deterioração, a produtividade nas organizações nunca esteve tão alta (Heloani \& Dacosta, 2002).

Como Moscovici (1988) afirmou, há um imenso descompasso entre progresso 
tecnológico e progresso social, em termos de qualidade de vida, nas organizações modernas.

O objetivo deste artigo não foi o de definir a QVT, trabalho ao qual muitos autores já se dedicaram com afinco (Walton, 1973; Trist, 1981; Nadler et alii, 1983; Huse \& Cummings, 1985; Wesley, 1979 Rodrigues, 1994; Fernandes, 1996; Vanconcellos, 1997). Contudo, ao partirmos do pressuposto de que há um processo de deterioração da QVT, faz-se necessário uma alusão ao conceito de QVT que foi assumido neste estudo.

Segundo seus princípios teóricos, muitos dos conceitos de QVT compartilham elementos comuns, diferenciando-se apenas em termos de maior ou menor abrangência quanto aos elementos contemplados. Assim sendo, no âmbito deste trabalho, optamos pela conceituação proposta por Walton (1973), baseada em oito categorias de QVT, já que sua abrangência nos permite também contemplar, indiretamente, pontos de vista de outros teóricos (Heloani \& Dacosta, 2002).

Tendo como ponto de partida as oito categorias de QVT propostas por Walton (remuneração justa e adequada, condições de trabalho, desenvolvimento de capacidades, oportunidade de crescimento, integração social, constitucionalismo, equilíbrio entre vida e trabalho e relevância social do trabalho na vida), investigamos como três dessas categorias vêm sendo tratadas na prática das organizações e quais efeitos estão produzindo na QVT dos jornalistas. A reflexãoque se segue é uma tentativa de sintetizarmos alguns dos indicativos mais notórios de deterioração da QVT frente a frente com algumas das categorias de QVT propostas por Walton (1973).

\section{Remuneração justa e adequada}

Estima-se que o número de trabalhadores americanos vítimas de downsizings entre 1980 e 1995 varie de um mínimo de 13 milhões para mais de 39 milhões (Sennett,
1998, p. 49). O executivo que sobrevive aos cortes corporativos acaba valendo, muitas vezes, por um grupo inteiro: trabalha-se por mais horas, mas sem qualquer ajuste incremental no salário relativo às horas trabalhadas.

Em um estudo nacional realizado pelo Isma/Brasil (International Stress Management Association, Brasil) com cerca de 556 white-collars de dezessete empresas privadas e dez públicas, de vários estados brasileiros, cerca de $63 \%$ dos executivos atribuíram as causas de estresse ao enxugamento nas empresas e aos programas de demissão voluntária.

Em estudo nacional realizado pelo IPSPP (Instituto Paulista de Stress, Psicossomática e Psiconeuroimunologia), com cerca de 1.500 executivos com nível universitário, $36 \%$ dos entrevistados afirmaram trabalhar acima de 11 horas por dia, sem qualquer compensação por horas extras.

Em pesquisa realizada pela American Management Association, "ter muito o que fazer e pouco tempo" apareceu no ranking mais alto de fatores que, segundo os executivos, geram mais intensamente frustração e estresse (Fraser, 2000).

A tecnologia (laptops, celulares, pagers, palm pilots, etc.) acaba por permitir que os executivos levem o escritório para qualquer lugar, tornando-se alcançáveis a qualquer momento. Em pesquisa realizada pela Yankelovich Partners, afirma-se que 53\% daqueles que possuem pagers já foram contatados durante as férias; $41 \%$ daqueles que possuem telefone celular tiveram que utilizá-lo para contatar seus escritórios durante as férias; $32 \%$ que possuem acesso à Internet tiveram que acessá-la durante as férias para checar seus $e$-mails; e, finalmente, $34 \%$ em algum momento checaram as secretárias eletrônicas de seus escritórios enquanto em férias (Fraser, 2000, p. 78). A fronteira entre vida no trabalho e pessoal torna-se cada vez menos delineada.

A mesma autora cita um dado desconcertante que demonstra que, mesmo desconsiderando o número de horas extras ou fora do escritório, os white-collars 
ainda assim, apesar de todo o esforço adicional, viram sua média salarial por hora sofrer um incremento de ridículos seis centavos de dólares desde 1973 (Heloani \& Dacosta, 2002).

\section{Ambiente de trabalho seguro e saudável e espaço total de vida}

A realidade do ambiente de trabalho vivida pelos executivos está bem distante do ideal de segurança e salubridade visualizado por Walton (1973). Estima-se que 35 milhões de white-collars estejam confinados por mais de oito horas/dia em cubículos que, segundo artigo da Business Week, encolheram de $25 \%$ a $50 \%$ ao longo dos últimos dez anos.

Muito mais do que criarem o tão propagado espírito de colaboração e abertura, espaços reduzidos de trabalho são mecanismos de constante submissão, além de pouparem às empresas significativos custos de instalação. A tecnologia garante às empresas um verdadeiro arsenal para se monitorar a produtividade e o empenho de seus executivos. Empresas como Exxon, Mobil Corporation, Delta Air Lines, e Ernst \& Young LLP utilizam um software chamado Investigator o "Grande Irmão" - que, como o próprio nome sugere, pode ser instalado em qualquer computador para investigar o número de teclas que são pressionadas, número de clicks no mouse, e todos os demais comandos eletrônicos utilizados por seus funcionários durante o dia (Fraser, 2000, p. 87).

Setenta por cento dos executivos entrevistados pelo Isma/Brasil responsabilizaram as novas tecnologias como principais causadoras de estresse. O suposto bem-estar, apregoado pelos entusiastas da tecnologia, não foi apenas substituído por cargas de trabalho excessivas e invasão da vida pessoal dos executivos mas também por desconfortos físicos: olhos irritados, dores no pescoço e nas costas, e talvez o mais sério, lesões por esforços repetitivos (LER/Dort) (Heloani \& Dacosta, 2002).

\section{Crescimento, segurança e integração social}

Torna-se difícil aceitar a idéia de carreira dentro do novo contexto organizacional se a própria questão de segurança no emprego vive constantemente abalada por sucessivos downsizings.

Atualmente, um jovem americano com um mínimo de dois anos de faculdade espera mudar de emprego ao menos onze vezes durante sua vida profissional, bem como mudar sua área de especialidade ao menos três vezes em 40 anos de trabalho (Sennett, 1998, p. 22).

Pelo fato de permitir às organizações a possibilidade de constante redefinição, a atual organização do trabalho baseada em networks (ou redes de trabalho), que substituiu as estruturas hierárquicas piramidais, acaba por tornar os critérios de promoção, carreira e até mesmo demissão completamente obscuros, já que não existem nem regras nem tarefas fixas.

Sennett (1998) ressalta os efeitos que a atual apologia à flexibilidade traz ao caráter das pessoas. Para o autor, a corrosão da idéia de "longo prazo" traz consigo o fim da confiança, da lealdade e do comprometimento mútuo. Nesse sentido, o discurso de "empregabilidade" torna-se conveniente para comunicar que as empresas não são mais responsáveis pela vida profissional de seus funcionários.

A dominação da atividade industrial pelo capital de risco teve consequiências danosas tanto para a QVT dos executivos quanto para a própria maneira com que as empresas passaram a ser julgadas em termos de sucesso. O sucesso passa a ser determinado segundo indicadores financeiros focados no curto prazo: ROI (return on investment) e valor de ações no mercado (Fraser, 2000).

A mentalidade financista das organizações também corrobora para a deterioração da integração social nas organizações (ou senso de coletividade, segundo Walton). Ao voltarem suas estratégias para o curto 
prazo, as empresas concentram-se tão-somente em corte de custos, muitas vezes baseados em downsizings. Esses últimos, por significarem demissões constantes, acabam por causar modificações contínuas das equipes de trabalho, destruindo o senso de coletividade e reduzindo cada trabalhador ao isolamento frente ao poderio das organizações (Pagès, 1987). Como Sennett (1998) bem observou, o sentido implícito de teamwork é tão-somente o de uma cooperação superficial. As pessoas não estão juntas por um ideal coletivo maior ou para ajudarem-se umas às outras, mas apenas para se pouparem de exposições solitárias frente aos demais (Heloani \& Dacosta, 2002).

O rompimento de vínculos de relações fundamentais para a manutenção e o fortalecimento da subjetividade humana atua de forma a desencadear o assédio moral, que tem sido compreendido, atualmente, como a exposição dos trabalhadores a situações humilhantes e constrangedoras, repetitivas e prolongadas, durante a jornada de trabalho. Consequientemente, as relações ficam mais desumanas e antiéticas e nelas predominam os desmandos, a manipulação do medo, a competitividade desenfreada e os programas de qualidade total associados à produtividade e dissociados da QVT. Quando a ênfase na produtividade leva à exclusão do sujeito, podem ocorrer algumas situações como:

- disseminação das práticas agressivas e naturalização dos desmandos administrativos, o que gera indiferença ao sofrimento do outro;

- desmotivação psíquica no trabalho;

- comprometimento da saúde física e mental;

- sensação de inutilidade, junto a uma progressiva deterioração identitária.

Em suma, a realidade corporativa quanto à QVT demonstra estar muito aquém do modelo teórico proposto por Walton. Os fatos apontados justificam o pressuposto de deterioração da QVT e nos motivam a investigar de que maneira os jornalistas estão reagindo a tal realidade.

O excelente estudo realizado por Dacosta (2001) investigou executivos com
MBA pela Harvard Business School, formados entre 1999 e 2000, com faixa etária girando em torno de 30 a 33 anos, experiência profissional de cerca de 8 a 10 anos, e que ocupavam cargos de gerência média em organizações de vários setores. Seu objetivo foi o de investigar se a posição privilegiada no mercado de trabalho estaria relacionada a melhores níveis de QVT. Ao contrário do que supunha a autora, a QVT era constantemente negociada por outros atributos como a remuneração.

\section{UMA PITADA ADORNIANA SOBRE ESTRESSE}

Na década de 1940, Theodor Adorno e Max Horkheimer elaboraram e tentaram desenvolver o conceito de indústria cultural, fundamental para o campo da comunicação, e utilizaram-se de uma violenta crítica à reprodução indiscriminada da obra de arte, ou melhor, à massificação da comunicação. Enquanto esses dois integrantes da chamada Escola de Frankfurt tentam resgatar e estudar a essência do sentido da expressão artística, ou seja, a semiótica da estética, outro pensador, Hans Selye, este mais voltado para as ciências naturais, tenta sistematizar uma série de observações que irão servir para a semiótica do corpo humano em situações específicas advindas do exterior. Daí nasce o conceito de estresse.

Tal como Adorno havia observado, quanto mais a obra de arte se reproduz, se multiplica, mais se distancia da sua originalidade, da sua essência. O conceito de estresse, na mesma década de 1940, também padecia do mesmo mal. Quanto mais se popularizava, mais se afastava de sua precisão conceitual e se vulgarizava. $\mathrm{Na}$ época, esse conceito de estresse, de termo obscuro e específico, oriundo da física significando o desgaste sofrido pelos materiais expostos a algum tipo de pressão ou força - tornou-se "tudo"; e, na esteira da mercantilização de nossa sociedade, que é algo igualmente abominado pelos frank- 
furtianos, servia e ainda se presta até para a venda de complexos vitamínicos. Expressões do tipo "no stress", "já acordei estressado", "o amor também é estressante", "o estresse dá emoções" e até "gerenciamento por estresse" não são incomuns. Urge, portanto, que sejamos um pouco adornianos e que tentemos resgatar de forma bem sintética, mas correta, o seu sentido original.

Segundo o conceito clássico de Hans Selye (1965, p. 64), “O estresse é o estado manifestado por uma síndrome específica, constituída por todas as alterações nãoespecíficas produzidas num sistema biológico”. Já para Lipp e Malagris (1995, p. 279) “estresse é definido como uma reação do organismo, com componentes físicos e/ ou psicológicos, causada pelas alterações psicofisiológicas que ocorrem quando a pessoa se confronta com uma situação que, de um modo ou de outro, a irrite, amedronte, excite ou confunda, ou mesmo que a faça imensamente feliz". Assim sendo, no nosso entender, o estresse pode ser definido como o esforço despendido por determinado organismo diante de determinada demanda externa, seja essa solicitação excessiva ou moderada, boa ou ruim.

Os estressores externos são todos os eventos, bons ou maus, que ocorrem na vida da pessoa, no seu mundo externo, como morte, promoção, dificuldades financeiras, enfim, eventos que constam da lista da Escala de Reajustamento Social de Holmes e Rahe (1967). Os estressores internos pertencem ao mundo das cognições do indivíduo, seu modo de perceber o mundo, seu nível de assertividade, suas crenças, seus valores, suas características pessoais, seu padrão de comportamento, suas vulnerabilidades, sua ansiedade e seu esquema de reação à vida (Lipp \& Malagris, 1995, pp. 280-1).

Em momentos de tensão existe uma quebra do equilíbrio interno, que ocorre devido à ação exacerbada do sistema nervoso simpático e à desaceleração do sistema nervoso parassimpático. Por isso, o conceito de homeostase torna-se fundamental para o entendimento do mecanismo do estresse, considerando-se que a principal ação do estresse é justamente a quebra do equilíbrio interno (Lipp \& Malagris, 1995, p. 280).

\section{JORNALISTAS:}

\section{TRABALHO X QUALIDADE DE VIDA}

Considerando que o jornalismo se torna cada vez mais uma atividade "informatizada" e regulamentada, parece-nos importante estudar as conseqüências desse processo na presente conjuntura histórica. Verificamos que faltam estudos sistemáticos acerca da atividade do jornalista como sendo propiciadora de estresse e de outras doenças ocupacionais. A experiência clínica nos leva a supor que o estresse nesta área advém sobretudo do trabalho que faz do jornalismo uma profissão de risco e também de morte precoce.

Pesquisas da Organização Internacional do Trabalho (OIT), junto a sindicatos de jornalistas, demonstram uma tendência nada promissora para essa profissão: devido às doenças insidiosas $\mathrm{e}$, portanto, de difícil diagnóstico precoce, parte significativa desses profissionais não alcança sequer a aposentadoria. Ademais, a partir da implantação de novas tecnologias nas redações nacionais, os usuários - jornalistas em sua maioria - se vêem cada vez mais diante dos Distúrbios Osteomusculares Relacionados ao Trabalho (Dort).

Tais perspectivas, portanto, consideram, respectivamente, a existência de uma relação negativa entre trabalho e saúde mental e entre modos de gestão e saúde em geral. Infelizmente, fatores como a natureza do trabalho e aspectos intrapsíquicos ou de personalidade ainda não são devidamente considerados por alguns pesquisadores na etiologia do estresse.

\section{VOLTA DO SUJEITO?}

O presente artigo pretende contribuir para um aprofundamento que auxilie uma melhor elucidação das relações de traba- 
lho, cuja compreensão é fundamental para a reflexão sobre aqueles que ajudam a formar, diariamente, nossa opinião. Diferentes saberes do campo científico, concernentes à temática do trabalho, vêm, paulatinamente, considerando a questão da identidade e da subjetividade.

Efetivamente, a temática da subjetividade, outrora objeto de estudo da psicologia, é crescentemente abordada pela sociologia do trabalho. Nas descrições a respeito da reestruturação produtiva, por exemplo, verifica-se uma presença significativa da discussão da subjetividade.

Dialeticamente, observa-se um movimento inverso, no qual disciplinas oriundas da psicologia se reformulam, ou mesmo se constituem, sob a influência do novo perfil assumido pela sociologia do trabalho. A psicanálise sai do seu gueto mais individualizante e dirige seu olhar não somente para o campo social e cultural, mas também para os fenômenos grupais e organizacionais. Consolidam-se, de tal modo, saberes interdisciplinares, comoé o caso da psicanálise das organizações. Também se desenvolve com vigor, tangenciando tais abordagens mormente a partir da contribuição de Dejours, a psicopatologia do trabalho. Trata-se de uma disciplina que reformula as visões mais clássicas da psicologia do trabalho, ou seja, aquelas influenciadas pelos saberes administrativo, médico e da engenharia da produção (Dejours, 2001, pp. 11-26).

Esse autor se esforça para compreender as relações de sofrimento e prazer existentes no mundo do trabalho e sua articulação com os mecanismos de defesa do ego. Dentro do que intitula psicodinâmica do trabalho, Dejours investiga a existência de mecanismos de defesa individuais e, especialmente, aqueles engendrados coletivamente. Assim sendo, nesta linha de raciocínio, "A identidade constitui a armadura da saúde mental. Não há crise psicopatológica que não esteja centrada numa crise de identidade" (Dejours, 2000, p. 34).

Eugène Enriquez (1996, pp. 7-22) menciona a questão da subjetividade nos debates sobre o trabalho com prudência. Ele nos alerta para o fato de que a "volta do sujeito", presente nas reflexões da sociologia do trabalho e de outras áreas, particularmente nas da administração, corre o risco de produzir ideologias de gestão que reforcem fenômenos como o da alienação.

Destarte a dita "volta do sujeito", no contexto do "capitalismo estratégico", associa-se a um engodo apresentado pelas organizações aos indivíduos. Tal engodo caracteriza-se por tomar a subjetividade como um recurso a mais a ser manipulado. Tal vertente crítica da abordagem da subjetividade no trabalho, que é encabeçada por Enriquez, também se expressa nas considerações de Davel e Vasconcelos (1996). Estes afirmam que a subjetividade só será efetivamente considerada, e não apenas reconhecida, quando efetivamente afastada da lógica instrumental e economicista que reduz o ser humano "ao estado de engrenagem ou recurso”. E é o que, a nosso ver, deve ser sempre repelido.

\section{FREUD EXPLICA?}

Dissabores de ordem psicológica podem ter vários elementos geradores e uma intensidade e complexidade variáveis. Aspectos do desenvolvimento, modelos familiares, educação, sociabilidade, vida profissional, relações conjugais, situação financeira, fantasias, desejos, conflitos, entre outros elementos, concorrem na determinação de situações mais ou menos comprometedoras em relação ao equilíbrio psíquico.

As valorizações equivocadas das realidades psíquica ou social em relação à etiologia de problemáticas psicológicas são fruto e sintoma de uma total dificuldade do conhecimento em elaborar uma síntese entre o que se convencionou denominar indivíduo e sociedade. Conforme argumenta Elias, estabelece-se um abismo intransponível entre elementos que são inerentemente indissociáveis (Elias, 1994). Levando-se ao extremo as considerações de Elias, seria de certo modo inadequado nos referirmos às problemáticas psicológicas pura e simplesmente. Não obstante, sintomato- 
logias e problemáticas psíquicas, ainda que articulem o social e o individual, expressam-se não somente nas realidades coletivas mais amplas, como a dos grupos profissionais e classes sociais, mas também nos indivíduos, mesmo quando se possa considerar que a causalidade preponderante de um sintoma, convencionalmente considerado como psíquico, seja a da realidade social. Assim, é tendo como pano de fundo a ressalva de Elias que estaremos aqui fazendo referências às ditas "problemáticas psicológicas".

A supervalorização do aspecto individual e da realidade psíquica não deve ser debitada à psicanálise, a despeito de esta ter praticamente criado e difundido a noção de realidade psíquica. Freud, como demonstra Mezan (1985), foi um pensador da cultura e da realidade que, tal como demonstra Coelho (1995), sempre foi algo considerado não somente por Freud, mas por todos aqueles que, em sua prática clínica, preocuparam-se e preocupam-se em realizar uma análise e compreensão mais aprofundada dos fenômenos e conflitos singulares percebidos nos indivíduos. Segundo Laplanche (1988), a questão da realidade objetiva retorna ao longo da obra de Freud, mesmo quando, em nome do abandono da teoria do trauma, e em prol da conceituação de fantasia, o mesmo tendeu a recusá-la.

Para Freud a pulsão, conceito este intimamente relacionado ao desejo e à fantasia, possui um lastro no biológico (Freud, 1974). Ou seja, o psiquismo possui uma relação direta não somente com a realidade social, mas também com a realidade biológica e corporal. Essas continuidades entre indivíduo e sociedade, corpo e mente, nem sempre visualizadas, possivelmente por influências do cartesianismo e dos modos de pensar refratários à síntese, necessitam ser melhor investigadas e demonstradas. A psicanálise pode contribuir para um avanço no conhecimento em tal direção e, assim, multiplicar seus campos de aplicação, ao invés de ser colocada, inadvertidamente, no escaninho do psicologismo (Birman, 2000).
Os debates concernentes aos problemas psicológicos relacionados à gestão do trabalho e de funções ou atividades profissionais ganham cada vez maior relevância nas áreas de sociologia e de psicologia do trabalho. Quase sempre, a área de sociologia tende a enfatizar a causalidade externa das condições e natureza do trabalho quando aborda as problemáticas psicológicas. Os sintomas tendem a ser interpretados como fruto de situações sociais opressivas ou manipuladoras. Em tal perspectiva, poupase o indivíduo e culpabiliza-se o social, a gestão do trabalho, etc. O conflito psíquico é visto como mero resíduo do conflito social (Garcia, 1996, pp. 159-76). A psicologia, por sua vez, por vezes realiza uma psiquiatrização da problemática social, interpretando, não raramente, conflitos sociais como simples produtos de um intrincado jogo de forças intrapsíquico, mais relacionado à estrutura de personalidade do que à situação objetiva (Castel, 1990). A realidade social ou do trabalho é apontada como elemento coadjuvante, ou melhor, como fator desencadeante de uma problemática psicológica potencialmente presente na estrutura de personalidade. Nesse sentido, aquela só faria aflorar um conflito já existente. Tais dicotomias porém, como já foi apontado, devem ser superadas, para que se possa efetuar a construção de estudos e pesquisas mais complexos e aprofundados na área de saúde mental, trabalho e qualidade de vida.

A compreensão dos aspectos da dinâmica psíquica levou em conta possíveis nexos e influências entre estrutura de personalidade, gestão e natureza profissional, ou, ainda, entre saúde mental, organização do trabalho e atitude profissional. Foi pesquisada a relevância ou não do grau de incidência de estresse, assim como sua caracterização sintomatológica e etiológica. Assim sendo, os objetivos da pesquisa possibilitaram a construção de um estudo aprofundado sobre os aspectos psicopatológicos relacionados ao exercício do trabalho, no referido grupo profissional.

Conquanto seja possível nomear, de forma didática, as problemáticas pesquisa- 
das como psicológicas, psicopatológicas ou psicossomáticas, considera-se que as mesmas possuem particularidades que transcendem os aspectos convencionalmente tidos como subjetivos, uma vez que englobam aspectos objetivos, quer sejam mais amplos ou grupais - como a realidade socioprofissional, a escolaridade, a qualificação e a gestão do trabalho -, quer sejam mais individualizados, como a realidade corporal.

Apesar da importância dos aspectos objetivos na constituição das referidas problemáticas, os elementos convencionalmente tidos como subjetivos - como a fantasia, a estrutura de personalidade e a realidade psíquica - foram igualmente considerados, de modo a configurar uma compreensão mais afinada às suas multicausalidades etiológicas. Nesse sentido, buscou-se não somente precisar a incidência de problemáticas psíquicas em um determinado grupo profissional, mas compreendê-las em sua complexidade, levando em conta, concomitantemente, noções como realidade social e psíquica, estrutura social e de personalidade, ou ainda fatores desencadeadores internos e externos. Ou seja, noções pertinentes às disciplinas da psicologia que se interseccionam com a sociologia do trabalho, a saber: psicanálise das organizações e psicopatologia do trabalho. Vale porém ressaltar que também foram consideradas, na análise e pesquisa dos aspectos psicossomáticos da saúde dos trabalhadores, as contribuições da psicologia que se relacionam mais diretamente aos conhecimentos médicos, tais como as da psicologia da saúde e dos estudos especializados sobre estresse e demais doenças ocupacionais.

\section{SOBRE OS DEPOENTES}

O presente trabalho contou com a colaboração de 44 jornalistas ( 24 homens e 20 mulheres) das mais diversas áreas. Entrevistamos em profundidade (história de vida) metade dessa amostra. A média de idade foi de 35,22 anos, variando entre 20-60 anos. O critério de busca desses sujeitos estabeleceu-se, no início, por intermédio de pessoas ligadas à área de jornalismo e, depois, instalou-se de forma aleatória; nesse estágio, a amostra intencional, portanto qualitativa, foi dobrada. Posteriormente, entramos em contato telefônico para expor nossas intenções metodológicas e solicitar permissão para as entrevistas. Com o intuito de assegurar o sigilo dos depoentes, optamos por não mencioná-los nominalmente.

A coleta dos depoimentos foi conduzida em duas situações distintas: no local de trabalho e em suas residências, a critério do entrevistado. As entrevistas foram realizadas com profissionais da mídia impressa rádio e TV. Tal opção, no nosso entender, não compromete o rigor metodológico, considerando que o que nos importa não é uma homogeneização da coleta dos depoimentos, e sim a qualidade das narrativas obtidas.

Depois da aplicação dos questionários, foram realizadas entrevistas semi-estruturadas e, posteriormente, foram organizadas discussões grupais sobre seu conteúdo, com ênfase sobretudo nos aspectos psicológicos envolvidos no trabalho (tensão, atenção, frustração, satisfação, idealização, sofrimento, conflito, medo, etc.).

Resumidamente, a metodologia envolveu variadas formas de obtenção de dados quantitativos e qualitativos, em situações grupais e individuais, ou ainda verbais (entrevistas e dinâmicas) ou escritas (questionários e inventários). Esse procedimento metodológico misto propiciou uma análise que contemplou, da forma mais abrangente possível, tanto os dados gerais e generalizáveis, como também, como foi dito, aqueles mais individuais e irredutíveis a uma caracterização coletiva única.

\section{DISCUSSÃO DAS NARRATIVAS}

Todos os sujeitos, sem exceção, reclamam da falta de tempo para seus familiares, sendo que a maioria se queixa da dificuldade de constituir uma família. De acor- 
do com os narradores entrevistados, o trabalho influencia diretamente na família, como podemos observar pelos depoimentos a seguir: "O meu trabalho é que determina quanto tempo eu vou ter para a minha filha, pras outras coisas da vida [...] mas eu não tenho tempo pra namorar". Também podemos observar na narrativa abaixo momentos relembrados que caracterizam "a vida de casado": "A gente dorme na mesma cama, mas só se fala por telefone e isto é muito chato [...]".

No caso dos solteiros, observamos que a presença física, morar sob o mesmo teto, não garante efetiva convivência e comunicação:

“Quando eu chego, geralmente, ela [mãe] já tá dormindo e ela sai cedo e eu depois. Apesar de nós morarmos juntas a gente se vê muito pouco. Então, às vezes, ficamos a semana inteira sem se falar direito".

"Por causa dessa obrigatoriedade de horário eu não consegui equilibrar de forma que seja satisfatória para mim, a minha vida pessoal e a minha vida familiar [...]. Gostaria de ficar mais tempo com a minha filha e não fico, não gosto de deixar ela sozinha, mas tenho que deixar".

A idade média dos participantes é de 35,22 anos, sendo que a maioria está na faixa etária de 20 a 39 anos. Constatamos na narrativa a seguir o vínculo existente entre pouca idade e pequenos salários nos dias atuais. A lei da oferta e da procura continua vigente.

“[...] na redação, o cara chegava lá com uma lista de 10 pessoas sendo demitidas numa fornada só, aí botava 15 estagiários de graça. Desses 15, não sobrava nenhum, porque os caras tavam encantados com a profissão [...].Nós sofremos uma concorrência desleal de quem quer trabalhar de graça. Isso tá cheio”.

Chama a atenção o fato de alguns pesquisados relativizarem a eficácia da formação superior que tiveram no que se rela- ciona ao seu cotidiano de trabalho. Destacamos também que alguns depoentes desejaram ou intencionam cursar Direito, por julgar que tal conhecimento constitui peça essencial para melhor compreensão de questões jurídicas e defesas de pessoas:

"Acho fascinante Direito, acho muito bacana você poder saber das leis, dos seus direitos. Poder defender uma pessoa e argumentar com uma base legal [...]É uma questão de cidadania [...]. Nunca fui processada, mas já testemunhei em processos de colegas".

“A maioria dos jornalistas sofre processos".

"A minha formação de jornalista foi uma negação. O conteúdo programático, a questão da prática de estudo foi terrível [...]. Em jornalismo não se exige muito título, ou você é bom naquilo que você faz ou não [...]. Eu acho que a formação do jornalista é muito mais no dia-a-dia, no campo, na diversidade, na curiosidade, na vontade de procurar as coisas, do que sentar em um banco de faculdade [...]".

“A valorização que nós tivemos [...] no início dos anos 70, ela não existe mais. E o que é pior, ela não existe nem no jornal [...]. Tanto que eles conseguiram acabar com a obrigatoriedade do diploma. Hoje, qualquer um é jornalista, qualquer um trabalha em jornal [...]. Nossa profissão foi muito depreciada [...]. Na ECA, eu sinto diferença $\operatorname{sim}[. .$.$] eles valorizavam muito$ mais o conteúdo e as salas eram pequenas, tinham poucos professores e poucos alunos. Apesar da USP estar deficiente, perdendo dinheiro, capenga, ainda é a melhor [...]. Os professores ainda estão preocupados com a formação da gente e não simplesmente com o mercado [...]".

Como se vê, no que concerne à formação e à obrigatoriedade do diploma de jornalista, embora a discussão seja relativamente antiga, estamos longe de chegar a um consenso. A depreciação da profissão também costuma ser enfatizada: 
“É uma frustração para um jornalista ver as redações desse jeito [...]. Você vai lá e faz um teste com eles e eles não sabem escrever. Não sabem botar uma vírgula. Não sabem botar um acento [...]".

Dos sujeitos pesquisados poucos fizeram pós-graduação lato sensu. Em vários depoimentos observa-se a falta de tempo, a falta de dinheiro e a incerteza do futuro, tal como pode ser constatado nas narrativas a seguir:

"Fico pensando por que eu não estudei [...]. Hoje eu vejo que o meu tempo é tão curto e que algumas coisas ficaram lá pra trás [...]. Eu quero fazer uma pós [...]. Quero ir estudar nos Estados Unidos [...]".

"Eu acho que é fundamental eu voltar a estudar [...]. Como eu quero dar aulas [...]. Na verdade, é uma coisa assim, as redações te tomam muito tempo [...]. Você entra às nove e, às vezes, sai à meia-noite e não tem aqueles horários e você perde muitas aulas. Eu acho difícil até hoje. Eu acho que o tempo compromete muito mesmo, mas há necessidade de estudar [...]".

Vale a pena observar que a maioria dos sujeitos pesquisados tem um tempo igual ou inferior a vinte anos de profissão, o que nos sugere uma carreira relativamente curta.

Da fala desses narradores podemos inferir que, principalmente no início da carreira, as condições de trabalho são bastante desfavoráveis e penosas, sendo que quase todos os profissionais da área jornalística apresentam elevado turnover (às vezes 7 a 8 empregos) na busca de novas oportunidades e de melhores condições de trabalho.

"Fiquei lá só três meses porque a TV era realmente muito ruim, vários problemas, salário, condições para trabalhar [...]".

“Eu já fiz muita coisa. Coisas muito diversificadas [...]. Eu comecei fazendo revista e jornal de empresa [...]. Depois fiz revisão [...]. Depois como revisor no $\mathrm{E}$. [...]. Depois no antigo Diário Popular também como revisor. Me tornei repórter, saí e fui trabalhar no Diário, também como repórter de economia. Saí e fui trabalhar no Sindicato do ABC [...]. Lá eu fazia um jornal e uma revista, mas também fiz serviços de assessoria. Voltei para o Diário como editor-assistente, voltando para o Agora e Diário de São Paulo, como repórter [...]".

“Consegui um trabalho na rádio Tupi [...]. Nos finais de semana eu trabalhava de graça, não ganhava nada, só experiência e era um tipo de gincana onde você ficava em lojas, pontos comerciais [...]. O chefe da redação falou: ‘vem'. Então eu ia, eu arrumava a redação, varria a redação, fazia cafezinho, não ganhava nada [...]”.

Observamos a diversidade de funções e ocupações dentro da área do jornalismo. Ademais, um depoente nos tenta alertar para os perigos da polivalência e multifuncionalidade que caracterizam o “jornalista pósfordista" ou "pós-reestruturação produtiva". Parece-nos evidente que as mudanças no mundo do trabalho, em termos tecnológicos, impactaram de forma negativa a qualidade de vida dos trabalhadores-jornalistas, como podemos observar:

"[...] de uns anos para cá, piorou muito. Teve um período... que todos os jornais, as empresas tiveram seus ajustes aí. Teve cortes. Informatizaram as redações. Mudaram o sistema de impressão, então, isto já eliminou muita função... é um setor que foi extinto em todas as redações... Hoje o repórter é que fica responsável pelo texto. Ele tem que editar o seu texto também. Então, hoje, você tem muito menos gente nas redações fazendo muito mais coisas [...]. Teve um acúmulo de funções [...]. Os jornais todos enxugaram as suas estruturas e quem ficou tem muito mais acúmulo de coisas. Tem mais sobrecarga".

No que concerne ao tipo de trabalho, o repórter não se restringe mais à sua função tradicional, coleta de informações e análi- 
se. Hoje, além disso, elabora o próprio texto e, não raro, o revisa. Às vezes, torna-se também motorista...

"Ultimamente a gente não tem motorista. Você está dirigindo o carro, tem que cobrir o candidato $X[. .$.$] . Eu vou dirigindo o carro$ atrás dele, na Via Anchieta, e o motorista dele correndo, não tem como parar o carro [...]".

"Isto é extremamente ruim [...]. Este quadro se agrava drasticamente, porque está tendo demissão atrás de demissão [...]. Nestes últimos meses piorou muito. Todos os grandes jornais e revistas e rádios e TVs demitiram pencas de profissionais [...]. Redações cada vez mais enxutas. Salários cada vez mais baixos. Cada vez menos infraestrutura".

Quando analisamos a totalidade dos dados, temos que a maioria dos entrevistados trabalha de 41 a 60 horas semanais. Essa constatação leva-nos à reflexão de que a carga de trabalho da grande maioria dos trabalhadores-jornalistas supera, e muito, as prescrições legais às quais essa categoria profissional está submetida, cinco horas diárias acrescidas de mais duas horas extras. Assim, vale a pena observar que a média real diária supera em quase cem por cento a prescrita, ou melhor, é de quase 10 horas diárias.

"Só quem não ganha hora extra é o jornalista [...]. Se você está contratado para ganhar sete horas e você trabalha doze, danese. Eu cheguei a trabalhar vinte e uma horas seguidas, dentro da redação [...]".

"Algumas pessoas pediram as contas, outras pessoas foram demitidas. Diminuiu um pouco o número de funcionários. Tô fazendo um horário meio maluco: um dia eu entro à tarde, outro dia eu entro de manhã. Tem que matar um leão por dia [...]".

“Acho que o mercado jornalístico nunca esteve tão ruim como está agora. Fecharam-se muitas portas. A carga de traba- lho é muito grande. A jornada é muito alta. A exigência é muito grande e o retorno é pouco. Se você não quer, a porta da rua está aqui e tem fila [...]. Fazem a mesma coisa que você faz e com um salário menor $[\ldots]$ ”.

O excesso de trabalho torna-se tão recorrente que metáforas tais como "matar um leão por dia" se repetem: "É como se tivesse que matar um leão por dia. Às vezes você luta bastante com o leão e fala 'eu venci e venci legal', mas às vezes você não vence legal $[\ldots]$ ".

Nas falas de vários sujeitos as conseqüências da informatização e automação se fazem sentir, externalizando um enxugamento das estruturas e um acúmulo de funções e tarefas.

"De uns anos para cá, piorou muito. Informatizaram as redações, isto já eliminou muita função. Hoje o repórter ficou responsável pelo texto [...]. Ele tem também de editar o seu texto [...]".

"Legalmente, a gente tem uma jornada de cinco horas mais duas. Duas são consideradas horas-extras. Todo mundo faz mais que sete horas. Faz oito, nove, dez, onze, doze, treze [...]. Os jornais não pagam horas extras e você nem cobra [...]. Acaba criando uma inversão: se a pessoa faz apenas o que deveria ser a sua jornada, passa por privilegiado. Até as outras pessoas acham estranho".

"Eu entrava às dez horas da manhã e saía às dez horas da noite [...]. Eu trabalhei na Record, era uma loucura. Não tínhamos férias, nunca tive férias [...]. Era tudo um bando de loucos [...]. Eu me incluo [...]".

O “mundo da vida”, a esfera particular, em muitos casos se confunde com a própria atividade profissional, como fica claro nas seguintes narrativas:

"Eu sou jornalista o tempo inteiro. Vida pessoal e vida do trabalho, elas se interpõem $[\ldots]$ "... 
“Oficialmente são sete horas. Mas, normalmente, a gente faz dez, nove, doze [...] é uma jornada puxada [...]. Você faz plantão nos finais de semana, carnaval você trabalha, eleições você trabalha, feriado você trabalha [...]. A folga é no Natal ou no Ano Novo [...]. A jornada é bastante rigorosa, cruel. Não temos horários fixos de trabalho, para comer [...]. Às vezes entro a uma, às vezes saio à meia-noite [...]. Eu já entrei aqui às oito e saí às quatro da manhã".

"Acho que o pior que tem na profissão é o plantão".

"Após um dia de trabalho, eu me sinto um caco $[\ldots]$. Ah, me dá vontade de tomar um litro de maracujina [risos]".

"Deixo de estar na minha casa, com minha mulher. Eu deixo de estar visitando a minha mãe, pelo jornalismo [...]. Cem por cento do tempo você fica ligado [...]. Então, funciona assim, como fonte de informação".

"Eu acho que influencia a gente assim. A gente acabou de casar e a gente se viu pouco [ri] [...]. Pouquíssimo, pouquíssimo, pouquíssimo assim".

"Eu não vivo para trabalhar, eu trabalho para viver... Eu trabalho na minha casa, eu trabalho junto com a minha esposa. Então, não tem como separar a minha vida pessoal da minha vida profissional [...]. É difícil dissociar uma coisa da outra... A vida pessoal e a profissional estão completamente interligadas".

"Eu acho que a minha vida pessoal e o meu trabalho não são coisas díspares [...]. A minha motivação de viver tá relacionada ao orgulho que eu tenho do que eu faço".

"Sexta-feira, que é o dia da alegria de todo mundo, que é normal, menos para jornalista, que nunca é normal, é o pior dia porque existe uma coisa chamada pescoção. Você fecha o jornal do sábado e fecha o do domingo também, então sai de madrugada [...]".
Chama a atenção o fato de que a maioria dos depoentes, apesar da falta de infraestrutura e de outras demandas, faz da profissão um verdadeiro fetiche. Os jornalistas gostam, e muito, do que fazem, alguns nutrindo verdadeira paixão por sua atividade.

“Um salário superbaixo, fiquei um tempão trabalhando com ele [...]. Bem baixinho mesmo [...]. Mas eu gostava do que eu faço. Às vezes, até esquecia de receber o salário, de tanto que eu gostava e gosto ainda" (profissional recordando seu início de carreira).

"Eu sempre gostei muito da minha profissão. Eu sempre fui trabalhar com muito entusiasmo [ri], cantarolando não, mas eu ia feliz. Quando eu estou escrevendo, eu me sinto bem. Isso me satisfaz muito. Fazer uma ligação (dar notícias e orientar o leitor). A pior coisa para o jornalista é ele não ter um fato para trabalhar, porque é a matéria-prima".

"Escolhi por gostar, principalmente, de rádio e comunicação... Pela paixão pelo rádio e por gostar de algo ligado ao social. Um trabalho que eu gosto, mas que é estressante"

"Eu trabalho em um jornal que é policial e é um momento um pouco tenso [...]. Eu não gosto de correria. Às vezes, eu tenho de fazer, e isso me incomoda um pouco. Essa parte de correria, com toda sinceridade, eu não gosto. Me incomoda. Eu tenho medo de bater a viatura [...]".

"Eu gosto de redação, apesar de sofrer. Eu acho que é que nem cachaça. Você vicia [...]. O nível de adrenalina é muito forte, assim, e você vicia. Fica escravo dessa coisa".

A maioria esmagadora dos profissionais entrevistados possui uma carga de trabalho excessiva, o que lhes dificulta o exercício de um outro tipo de atividade fora do jornalismo. 
"Eu trabalhava durante o dia, na Unipress, das nove às dezoito e entrava no Estadão, às vinte e duas horas, e ficava até às duas da manhã...".

"Sempre são doze horas de trabalho, na segunda-feira, na revista. Terça-feira eu dou aula cedo. Terça e quarta eu dou aula cedo e à noite. Então tem um ritmo mais puxado. Eu acordo umas seis horas porque as aulas começam às sete e meia e vão até às onze... Então, normalmente terça e quarta eu não almoço $[\ldots] "$.

Faz-se mister comentar que no transcorrer das entrevistas houve o surgimento espontâneo, geralmente acompanhado de forte carga emocional, de falas relacionadas a competição, desunião, inveja e falsidade entre colegas de profissão. A menção à falta de ética no manejo dos fatos e informações não foi rara.

"Há ciúmes de um lado e intrigas de outro. Eu sei que jornal é uma fábrica de intrigas...”.

“Tudo lá é muito tenso. Tudo é no grito e aí eu fiquei doente... esta afonia”.

"Revisões foram extintas nas redações, porque foram informatizadas [...] achei um absurdo [...]. Imagina, extinguir o departamento e não dar uma satisfação para a gente e a gente nem sabia até quando ia trabalhar".

“Todo ambiente tem competição, tem arrogância e tem inveja. Aí a gente já não se dói tanto ... A gente aprende a lidar com isso".

“Não existe ética... Ética hoje é dinheiro".

"Ética? Não tem nenhuma. Pra você fazer um programa assim, você não tem que ter. Se você for um pouquinho ético, você é derrubado do jornal...".

“O jornalista é uma categoria absurdamente desunida... [...]. Esse sindicato de merda, e quem faz o sindicato são os jornalistas. Eu sou sindicalizado. Se você per- guntar aqui quem é mais, não tem. Ninguém mais é”.

"Isso é uma fábrica de loucos. Estou trabalhando e tudo cai na minha mão. Fiz três, quatro matérias. Eles acham que eu sou o quê? Parece um liquidificador batendo matéria $[\ldots]$ "..

“Na televisão há uma competição muito grande... Quantos querem aparecer? Então, há uma disputa muito grande e, às vezes, acaba não sendo feita de maneira correta, de maneira leal. Há muita deslealdade, muita [...]. Falam mal um do outro, fazem futrica, querem te derrubar, querem derrubar o outro, entendeu? Isso é uma constante dentro do meio. Então, você não sabe em quem pode confiar. Você está conversando com alguém que, às vezes, tá querendo a sua cabeça. Depois, mais à frente, você percebe que a pessoa trabalhou contra você o tempo todo".

"Existe um desfile de egos muito grande, principalmente na redação".

"Todo mundo narcisista, todo mundo quer aparecer".

“Algumas pessoas são muito, muito desagradáveis. No jornal, era o famoso leãoserra, que era chamado de rei dos animais, porque ele começava a esbravejar no meio da redação, humilhando um repórter [...]”.

Chamou-nos bastante a atenção o fato de que a compressão dos salários constitui realidade tão recorrente que chega a "naturalizar-se" nos discursos de algumas chefias e narradores.

"Sei de colegas que ouviram coisas horríveis. Uma garota na minha sala foi falar sobre o aumento de salário e o chefe respondeu assim: 'ah, vocês vão continuar tomando no cu até o fim do ano"”.

"Um salário, assim, superbaixo. Fiquei um tempão trabalhando com ele, com salário assim...". 
“O jornalista acaba cumprindo funções que não deveria cumprir, não recebe hora extra e não tem muito poder de defender-se [...]".

“O que eu menos gosto é da insegurança financeira [...]. Da desregulamentação total do mercado [...]. Não ter seguridade social de espécie alguma [...]. Me tira o sono...".

"Com vinte e dois anos eu estava editando Economia... Eu já estava ganhando bem e já tinha um cargo razoável [...]. Hoje, salários cada vez mais baixos".

"Na nossa profissão, direitos trabalhistas não existem mais. Alguém inventou há algum tempo atrás a bendita prestação de serviços. Todo mundo emite nota, sabe? Empregado com carteira assinada, em rádio e televisão, é uma mosca branca. A não ser o pessoal operacional...".

"Eu fiquei insatisfeito porque [...]. Não senti um reconhecimento em termos de salário $[\ldots] "$.

Podemos observar que os sujeitos da pesquisa têm consciência das dificuldades que o trabalho acarreta para o convívio familiar. Contudo, não conseguem visualizar uma saída para essa colonização do mundo do trabalho (sistêmico) em relação ao mundo da família (da vida) (Habermas, 1990).

"Meu período de férias é em abril, fico longe da família [...]. Se eu estou pronta para ir a uma festa com ele [companheiro] e meu chefe liga e fala que aconteceu um acidente sério e diz: 'preciso de você', então eu vou".

"O trabalho acaba com a minha vida pesso-

al. Eu, às vezes, gostaria de ter uma vida normal, sabe [...]. Sou um cara muito caseiro. Gostaria de poder estar com a minha mulher, com os meus filhos. Me faz uma falta desgraçada. Não tem jeito".

"A gente acabou de se casar e a gente se viu pouco [ri]. Eu chego em casa, troco meia dúzia de palavras [ri] [...]. não agüento mais falar. O relacionamento sexual cai, cai, cai. Por mais que você queira 'tá' ali, não adianta [ri]".

"A gente ainda não se animou a colocar os pimpolhos no mundo [...]. Um dos motivos é essa questão de instabilidade. A gente não sabe se tá no Brasil, se tá fora do Brasil. Se tem salário esse mês, se não tem $[\ldots]$ '.

"Moro sozinho e trabalho feito louco. Apesar de ser uma pessoa meio fechada [...] me dou bem com minha família e vou visitar meus pais regularmente".

"Eu fiquei casado até os trinta. Me separei! Fui morar com uma menina [...]. Me separei [...]. Eu moro com a minha terceira esposa [...]. Eu deixo de estar na minha casa, com a minha mulher. Eu deixo de estar visitando a minha mãe pelo jornalismo [...]".

"Ela [esposa] saía de manhã para ir para o consultório, eu tinha terminado o café da manhã, ia começar a ler o jornal, parou um carro da televisão e falaram: 'Pega tuas coisas e vamos para a Argentina. Tá tendo um levante de militares e a gente tá indo pra lá [...]'. Ela [esposa] ligou a televisão, quando acordou, eu estava ao vivo, no meio do tiroteio. Ela [esposa] falou que viver comigo é uma aventura muito difícil. 'Não dá, é muito complicado viver com você' [ri]. Aí me separei dela [...]".

"Horrível. Horrível, eu me sinto muito mal. Eu vivo com eles, eu vivo para eles e não consigo administrar. Eu sinto falta, porque eu queria conversar com a minha família [...]. Já teve dias que eu sentei e chorei $[\ldots] "$.

Muitos dos nossos depoentes demonstraram apreciar atividades diferenciadas de lazer, mas só têm acesso, com maior freqüência, àquelas menos onerosas, tais como cinema, ida a restaurantes etc. As que exigem maior disponibilidade financeira tornam-se mais raras ou só se realizam jus- 
tamente quando perdem sua qualidade de diversão, ou melhor, quando proporcionadas pelo trabalho. Viajar, atividade tão desejada e tão postergada, serve de exemplo.

"Eu não tenho tido muito tempo pro lazer. Eu tenho tido muito trabalho, muitas preocupações [...]. Não tenho muito lazer [...]. Cinema [...]. Eu gosto muito de comer [...]. Bater papo".

"Eu gosto de ir ao cinema [...]. Ir ao parque porque lá dá pra caminhar [...]. Na verdade, não dá tempo de fazer muita coisa, dá pra ler. Viajar muito eventualmente".

"Eu faço caminhada [...]. Leio muito. Gosto muito de cinema, teatro. Meu lazer é predominantemente cultural. Viagens, eu viajo tanto a trabalho".

\section{"Lazer? Ultimamente nada".}

“Ultimamente eu não tenho saído muito. Eu estou terminando um trabalho de TCC. O meu único lazer está sendo a ginástica”.

"Eu adoro dançar. Eu gosto muito de ir ao cinema e ao teatro. Mas eu tenho chegado em casa tão cansada que eu quero ler, mas não dá pra ler não".

"É ler... Eu sempre gostei de música... Gosto muito de caminhar [...] mas é problema de tempo quando não é limitação financeira [...]. Eu acabo não viajando como gostaria".

“Lazer é ridículo. Meu lazer é ler. É ir ao cinema [...]. Tentar descobrir lugares [...]. Eu soube que existe uma padaria no Mosteiro de São Bento".

"No verão, eu faço churrasco e uso a piscina aqui de casa [...]. Costumo sair à noite [...]. No fim de semana fico quieto na praia e tal".

"Faz tempo que eu não tenho uma viagem de lazer. Eu faço viagem de trabalho, mas eu me divirto pacas...".
"Esporte. Eu leio também. Gosto de jogos de computador... E gosto muito de sair para tomar cerveja com os amigos".

A escala de pontuação, baseada na lista de eventos de vida de Holmes e Rahe, traduzida por Marilda Novaes Lipp (1990), foi criada para avaliar as fontes externas de estresse, isto é, mudanças que ocorrem na vida e que podem produzir estresse. De acordo com esse instrumento, os resultados mostram que a maioria dos sujeitos tem maior probabilidade de estressar-se devido à quantidade gasta de energia adaptativa.

Quando pedimos para os entrevistados responderem a questões do "Manual do Inventário de Sintomas de Stress para Adultos de Lipp (ISSL, 2000)", nosso intento não era o de apenas identificar, de modo objetivo, a sintomatologia que o sujeito apresentava, e a fase em que se encontrava; mas também desejávamos aferir como esses depoentes interagiam com tal desconforto, considerando que todo ser humano pode, em certo momento de sua existência, ter pelo menos um sintoma de estresse, sem de fato possuí-lo. Também tínhamos plena consciência da possibilidade de o sujeito assinalar alguns itens e, apesar disso, o estresse não ser devidamente sinalizado.

“Quem diz não sou estressado está mentindo. Todos nós somos um pouquinho [...]. Eu já cheguei ter uma crise grave de stress a ponto de ser obrigada pelo médico a tirar licença $[\ldots]$ '.

"Manipular informações sigilosas. Eu acho que elas são, hoje em dia, os meus maiores fatores de stress".

“O que você reúne de informação é uma estupidez [...]. É tanta informação [...]. É uma coisa muito louca e te dá um stress violento. Isto é um fator de alto stress".

“Como eu não levo coisa pra casa, eu não levo preocupação [...]. Engano todo mundo e amanhã eu termino, mas não vou me estressar". 
“Há uns cinco meses atrás, eu tive problema de stress. Travou minha coluna e tudo. Fui para o médico e o médico falou: 'É stress. Tem de dar uma parada",.

"Sempre estressada, não. Eu tenho meus minutos de stress. Eu tenho picos".

"Me sinto, em muitas situações eu me sinto estressada. Por causa do trabalho. Por causa dessa nossa profissão. Existem situações em que você realmente convive com o stress. Ojornalismo é: 'tempo é dinheiro'”.

“Às vezes. Eu consigo perceber quando eu tô entrando numa fase de muito stress e daí eu já tento dar uma desligada [...]".

“Tem muita gente com LER, principalmente as pessoas da internet. Eu tenho um amigo afastado quinze dias por causa de stress [...]".

“Às vezes fico cansado mesmo. Travado. Acho que o stress é muito em função de achar que falta o tempo".

“Teve uma época, eu travei ‘brabo’ [...]. Eu não tinha mais fome e não estava dormindo. Eu deitava e não dormia [...]. Nossa, estou travando [...]. E a solução foi parar de fazer o trabalho [...]. Aí voltou ao normal".

"Sinto, sinto estressada pela carga de trabalho. Fico chateada, brava, rôo unha de monte, aí fico com mais dor de estômago, com dor de cabeça, o corpo grita".

"Eu tô um pouco, ultimamente. Eu tô lendo um livrinho da Sei-cho-no-iê. [...]. Lendo essas 'Sutras Sagradas' [...]”.

“Se eu não gostasse, se eu trabalhasse na rádio por obrigação, eu estaria mais estressada ... Porque o dia-a-dia cansa. Stress de muito som alto. Você tá vinte e quatro horas pensando em notícia.... às vezes não relaxo".

"Estressado? Constantemente, por causa dessa jornada de trabalho estafante, dessa esquizofrenia de atividades que é o contraponto dessa coisa da versatilidade. Você acaba tendo que ter vários focos ao mesmo tempo. Se seu pudesse ficar em uma coisa só, meu nível de stress seria menor. Mas não dá”.

A maioria absoluta dos sujeitos que se submeteram à nossa pesquisa apresenta estresse.

\section{INDICAÇÕES FINAIS}

Nesta pesquisa procuramos demonstrar que a deterioração da qualidade de vida no trabalho banalizou-se, ou melhor, naturalizou-se. Depreendemos do referencial teórico utilizado que, no atual sistema de produção, o trabalhador-jornalista é forçado a negociar a sua força de trabalho para a sua subsistência.

As organizações, pressionadas pelo processo de globalização, substituem cada vez mais o homem pela máquina, implementam novas tecnologias e obrigam o jornalista a adaptar-se freneticamente a elas. Assim sendo, o seu corpo, que é o seu instrumento de trabalho, se "ressente" e a sua mente se "surpreende" como se pode inferir por meio da observação dos consideráveis níveis de estresse. Afinal, como responderam dois de nossos depoentes, "isso é uma fábrica de loucos", "o ambiente era tão pesado que as pessoas morriam... de câncer”.

Procuramos investigar em que medida e de que modo essas mudanças impactaram a qualidade de vida desses profissionais formadores de opinião. Mais do que isso, preocupamo-nos em estudar a percepção desses jornalistas em relação à deterioração quanto à QVT.

Com base em uma abordagem dialética calcada no estudo das contradições do discurso - tal como já apregoava Max Pagès (1987) - que foram observadas nos relatos dos sujeitos ("é meio que amor e ódio, esse negócio aqui'”) elaboramos uma série de questões abertas e fechadas a serem analisadas, qualitativamente e em profundida- 
de. Ademais, também utilizamos outros instrumentos complementares, tais como o "Inventário de Sintomas de Stress, Qualidade de Vida e Escala de Reajustamento Social", com o objetivo de dar maior fidedignidade aos depoimentos colhidos.

Com certa desenvoltura e às vezes de forma catártica, nossos depoentes não só admitiram uma significativa deterioração de sua qualidade de vida, como alguns demonstraram desejo de mudança de atividade profissional, tendendo, em sua maioria, para a área jurídica. A maior parte desses profissionais admitiu a possibilidade de tornarem-se descartáveis e consideraram "natural" a contínua mudança de emprego. Como se isso não bastasse, ficou claro para nós que muitos dos sujeitos julgavam ser difícil conciliar trabalho e vida pessoal.

Não obstante haja um significativo grau de consciência no que concerne à deterioração da qualidade de vida, quase todos os sujeitos tentam adaptar-se, como podem, a esse fato, por meio de saídas individuais. Quanto à possibilidade de soluções mais coletivas, como, por exemplo, via sindicato, simplesmente descrêem, pois segundo um dos entrevistados "o jornalista é uma categoria absurdamente desunida... também este sindicato de merda...".

O mais preocupante na análise das entrevistas é um claro indicador de que as práticas organizacionais trouxeram, como efeito colateral danoso, não apenas a corrosão de certos valores básicos, mas, principalmente, a cisão da idéia de qualidade de vida e excelência no trabalho. Assim, a felicidade é sempre postergada e, em decorrência disso, também o tempo para a família, para os filhos, para o lazer e para o amor. Alguns chegam a alegar que fora do ambiente de trabalho só fazem o imprescindível, faltando tempo para namorar.

Como Richard Sennett (1998) bem apontou, o comportamento imediatista obstaculiza e descaracteriza o sentido de lealdade, amizade e confiança. As organizações dispensam seus trabalhadores com facilidade e estes "rebelam-se", envolvendo-se com as suas tarefas e alienando-se do grupo. A vivência do trabalho passa a ser um simples intervalo entre um emprego e outro e parece causar inevitavelmente a diluição da idéia de fim. Como é sempre possível recomeçar, cria-se a ilusão de que o sofrimento é sempre temporário e, portanto, suportável, desde que outras benesses sejam ofertadas.

Assim sendo, o sofrimento, que, para Cristophe Dejours (2000), deveria ser uma expectativa com relação à auto-realização, um estado mental que implicasse um movimento da pessoa sobre sua existência, passa a ser relegado à condição de estado temporário, dentro da ilusão de que o curto prazo torna tudo plausível... Se o próprio significado de vida mostra-se deteriorado pelo predomínio do efêmero, isto nos leva a acreditar que as iniciativas em prol da QVT parecem estar muito mais alinhadas com aspectos da profissão do que com uma genuína emancipação.

O trabalho parece não ser mais depositário de um processo de vivência e identificação coletiva. Com a competição cada vez mais acirrada, devido aos inúmeros processos de reestruturação produtiva e enxugamentos exigidos pela organização, a questão ética fica ainda mais comprometida. Manipulação das informações, humilhações no trabalho e ausência de sindicalização parecem ser recorrentes: "Se você for um pouquinho ético, você é derrubado do jornal...".

Se quase todos reconhecem haver uma instrumentalização da subjetividade no ambiente de trabalho, por que não desistem? Por que insistem na profissão? A dúvida que se colocava, afinal, era a de por que jornalistas, geralmente bem qualificados e informados, formadores de opinião, se sujeitarem a condições como estas: "Vocês vão continuar tomando no cu até o fim do ano". O que se concluiu pelos depoimentos é que a maioria desses sujeitos simplesmente ama seu trabalho, são apaixonados pelo que fazem, fetichizam sua profissão.

Apesar do glamour, do fetiche pelo jornalismo, como já vimos, alguns buscam outras saídas pois, ao contrário de outros 
colegas, não suportam mais adiar a felicidade e temem não mais agüentar o ritmo de trabalho por muito tempo, ou melhor, até a aposentadoria. Isso fica evidente pelas seguintes falas: "Hoje a redação é uma padaria, é uma linha de montagem...”.

Ao contrário do que supõem alguns entrevistados, as novas práticas políticoeconômicas e culturais não podem ser revertidas a partir de soluções individuais, inócuas no atual contexto mundial, tampouco por meio das organizações jornalísticas, pois o processo foi criado em seu próprio benefício. Se há um caminho para uma reversão dessa lógica, este deve iniciar-se no fortalecimento do coletivo, dos órgãos de representação, tal como associações de classe e sindicatos. Assim sendo, faz-se necessário que as instituições que formam os formadores de opinião, tais como universidades, comecem desde cedo a cultivar o senso ético, o amor à verdade e a reflexão sobre a felicidade, como nos ensinou Teilhard de Chardin (s.d.):

"Sem dúvida, como todos os outros seres animados, o Homem deseja essencialmente ser feliz. Mas, nele, essa exigência fundamental toma uma forma complicada e nova. Com efeito, o Homem não é somente um ser vivo mais sensível e mais vibrante que os outros. Por força de sua 'hominização', ele se tornou um ser vivo reflexivo e crítico. Ora, esse dom da reflexão acarreta por si mesmo duas temíveis propriedades, quais sejam: a percepção do possível e a percepção do futuro - duplo poder cujo aparecimento basta para perturbar e dispersar a ascensão até então tão coerente e tão límpida da Vida. Percepção do possível e percepção do futuro, ambas se conjugando para tornar inexauríveis e para dissipar em todos os sentidos tanto os nossos temores quanto as nossas esperanças...".

\section{BIBLIOGRAFIA}

ADORNO, Theodor; HORKHEIMER, Max. A Dialética do Esclarecimento. Rio de Janeiro, Jorge Zahar, 1986.

BIRM AN, Joel. Entre Cuidado e Saber de Si: sobre Foucault e a Psicanálise. Rio de Janeiro, Relume Dumará, 2000.

CASTEL, Robert. O Psicanalismo. Rio de Janeiro, Graal, 1990.

CHARDIN, Teilhard de. Mundo, Homem e Deus. São Paulo, Cultrix, s.d.

COELHO, Nelson. A Força da Realidade na Clínica Freudiana. São Paulo, Escuta, 1995.

DACOSTA, Maria Carolina. A Questão da Deterioração da Qualidade de Vida no Trabalho na Visão dos "Bem-

sucedidos". Dissertação de mestrado. São Paulo, FGV, 2001.

DAVEL, Eduardo; VASCONCELOS, João (orgs.). "Recursos" Humanos e Subjetividade. São Paulo, Vozes, 1996.

DEJ OURS, Christophe. A Banalização da Injustiça Social. São Paulo, FGV, 2000. . A Loucura do Trabalho - Estudo de Psicopatologia do Trabalho. São Paulo, Cortez, 2001.

ELIAS, Norbert. A Sociedade dos Indivíduos. Rio de J aneiro, Jorge Zahar, 1994.

ENRIQUEZ, Eugène. Da Horda ao Estado: Psicanálise do Vínculo Social. Rio de Janeiro, Jorge Zahar, 1996.

FERNANDES, E. Qualidade de Vida no Trabalho. Salvador, Casa da Qualidade, 1996.

FRASER, Jill A. White-collar Sweatshop: the Deterioration of Work and its Rewards in Corporate America. New York,

W. W. Norton \& Company, 2000.

FREUD, Sigmund. O Mal-Estar na Civilização. Rio de Janeiro, Imago, 1974.

As Pulsões e seus Sestinos. Rio de Janeiro, Imago, 1974. 
GARCIA, Sylvia Gemignani. "Cultura, Dominação e Sujeitos Sociais", in Tempo Social. São Paulo, USP, out./ 1996, pp. $159-76$.

HABERMAS, Jürgen. Para a Reconstrução do Materialismo Histórico. São Paulo, Brasiliense, 1990.

HARVEY, David. A Condição Pós-moderna - uma Pesquisa sobre as Origens da Mudança Cultural. São Paulo, Edições Loyola, 1992.

HELOANI, Roberto; DACOSTA. "QVT: Fatos, Reflexões e Novos Horizontes", in (Simpoi) V Simpósio de Administração da Produção. São Paulo, FGV-SP, 2002.

HELOANI, Roberto. Organização Trabalho e Administração: uma Visão Multidisciplinar. São Paulo, Cortez, 2000. . Gestão e Organização no Capitalismo Globalizado: História da Manipulação Psicológica no Mundo do Trabalho. São Paulo, Atlas, 2003.

- Mudanças no Mundo do Trabalho e Impactos na Qualidade de Vida do Jornalista. Relatório de

Pesquisa no 12/ 2003. São Paulo, FGV-SP (NPP - Núcleo de Pesquisas e Publicações).

HOLMES, T. H. ; RAHE, R. "The Social Readjustment Rating Scale", in J ournal of Psychosomatic Research, 4, 1967, pp.189-94.

HUSE, E.; CUM MINGS, T. Organization Development and Change. St Paul, Minn, 1985.

LAPLANCHE, Jean. "Da Teoria da Sedução Restrita à Teoria da Sedução Generalizada", in Teoria da Sedução Generalizada e Outros Ensaios. Porto Alegre, Artes Médicas, 1988.

LIPP, Marilda Novaes. Como Enfrentar o Stress. Campinas, Ícone, 1990.

_. _ _ _ _ _ . Manual do Inventário de Sintomas de Stress para Adultos de Lipp (ISSL). São Paulo, Casa do

Psicólogo, 2000.

LIPP, Marilda; ROCHA, João Carlos. Stress, Hipertensão Arterial e Qualidade de Vida. Campinas, Papirus, 1994.

LIPP, Marilda; MALAGRIS, Lúcia. "Manejo do Estresse", in Bernard Rangé (org.). Psicoterapia Comportamental e

Cognitiva: Pesquisa, Prática, Aplicações e Problemas. Campinas, Editorial Psy, 1995.

MEDINA, Cremilda. Entrevista: o Diálogo Possível. São Paulo, Ática, 1995.

MEZAN, Renato. Freud: o Pensador da Cultura. São Paulo, Brasiliense, 1985.

MOSCOVICl, Fela. Renascença Organizacional. Rio de Janeiro, Livro Técnico e Científico, 1988.

NADLER, D. A. et alii. Comportamento Organizacional. Rio de Janeiro, Campus, 1983.

PAGĖS, Max et alii. O Poder das Organizações. São Paulo, Atlas, 1987.

QUEIROZ, Maria Isaura Pereira. "Relatos Orais: do 'Indizível' ao 'Dizível'", in Ciência e Cultura. São Paulo, mar.I

1987, pp. 272-86.

RODRIGUES, M. V. C. Qualidade de Vida no Trabalho. Petrópolis, Vozes, 1994.

SELYE, Hans. Stress, a Tensão da Vida. São Paulo, Ibrasa, 1965.

. "History and Present Status of the Stress Concept", in L. Goldberger; M. Breznit (eds.). Handdbook of

Stress: Theoretical and Clinical Aspects. London, Free Press, 1984.

SENNETT, Richard. The Corrosion of Character. New York, Norton \& Company, 1998.

THIOLLENT, Michel. Metodologia da Pesquisa-ação. São Paulo, Cortez, 2002.

TRIST, Eric. The Evolution of Socio-technical Systems. Toronto, Ontario Quality of Working Life Centre, Occasional Paper, number two, june/ 1981.

VASCONCELLOS, Marcos. Excelência e Humanização da Produção. Monografia de professor titular. FGV-SP, 1997. WALTON, Richard. Quality of Working Life: What Is It? Sloan Management, 15(1), 1973, pp. 11-21.

WESLEY, William. "Problems and Solutions in the Quality of Working Life", in Human Relations, 32(2), 1979, pp. 11-123. 